Mots. Les langages du politique

$93 \mid 2010$

Figures et filiations dans le discours politique latinoaméricain

\title{
Filiations,polyphonie, théâtralité. Figures politiques tutélaires en Amérique latine
}

Pierre Fiala et Jean-Paul Honoré

\section{OpenEdition}

\section{Journals}

Édition électronique

URL : https://journals.openedition.org/mots/19826

DOI : $10.4000 /$ mots. 19826

ISSN : 1960-6001

Éditeur

ENS Éditions

Édition imprimée

Date de publication : 1 juillet 2010

Pagination : 5-8

ISBN : 978-2-84788-237-5

ISSN : 0243-6450

Référence électronique

Pierre Fiala et Jean-Paul Honoré, «Filiations polyphonie, théâtralité. Figures politiques tutélaires en Amérique latine », Mots. Les langages du politique [En ligne], 93 | 2010, mis en ligne le 01 octobre 2012, consulté le 23 avril 2022. URL : http://journals.openedition.org/mots/19826 ; DOI : https://doi.org/ $10.4000 /$ mots. 19826 


\section{Filiations, polyphonie, théâtralité. Figures politiques tutélaires en Amérique latine}

Confrontée durant des décennies aux incertitudes et aux violences politiques (Garibay, Périès éd., 2007), l'Amérique latine connait aujourd'hui un tournant démocratique historique (Rouquié, 2010) qui s'inscrit dans une prise de conscience collective de ses forces progressistes (Couffignal éd., 2009). Depuis 2005 en effet, les consultations électorales, au Honduras, au Nicaragua, en Bolivie, au Chili ${ }^{1}$, en Équateur, au Costa Rica, en Colombie, plus récemment au Paraguay, au Brésil et au Venezuela, ont enregistré des résultats largement favorables à la gauche, voire des victoires importantes de celle-ci. Ce virage n'est certes ni homogène ni absolu, mais on peut considérer qu'après de longs épisodes de dictatures et de pouvoirs militaires, « les urnes commencent à être la façon dont les Latino-Américains canalisent leur demande» (Le Monde), leur mécontentement ou leur frustration. Comment entendre, dans ce contexte, la montée au pouvoir des personnalités qui incarnent cette gauche, très hétérogène au demeurant : Luiz Inácio Lula au Brésil, Hugo Chávez au Venezuela, Evo Morales en Bolivie, Michelle Bachelet au Chili ou encore Daniel Ortega au Nicaragua? Comment lire les déclarations de leurs adversaires? On se propose d'entrer dans cette nébuleuse par l'analyse du discours politique des leaders et des figures archaïques dont ils se réclament, et dont la plus emblématique est Simón Bolívar.

Le discours politique latino-américain s'est construit, on le sait, autour de figures tutélaires porteuses de projets d'émancipation sociale et politique. C'est dans ses figures énonciatives, devenues quasiment mythiques, que les divers régimes politiques puisent, aujourd'hui plus que jamais, leurs répertoires et construisent leurs références idéologiques. Ils s'approprient ces sources en les fragmentant, en les amplifiant, en y sélectionnant des thématiques, des

Université Paris-Est Marne-la-Vallée, CEDITEC fiala@univ-paris12.fr

Université Paris-Est Marne-la-Vallée, CEDITEC Jean-Paul.Honore@@univ-mlv.fr

1. L'élection en février 2010 du dirigeant conservateur Sebastian Pinera n'inverse pas réellement la tendance, la présidente Bachelet, non rééligible, continuant à incarner un courant progressiste majoritaire dans le pays. 
champs lexicaux et des lieux argumentatifs, en les incorporant à de nouvelles mises en scène discursives ancrées dans l'évènementialité.

Les articles réunis dans ce dossier ${ }^{2}$ illustrent diverses modalités de cette réappropriation et de cette intertextualité. Diverses formations discursives propres aux Caraïbes, aux territoires andins et amazoniens en constituent le terrain. Elles sont centrées sur ces figures, héroïsées ou non, connues ou moins connues, autour desquelles se sont affrontés les discours. Ancrées dans la matérialité langagière, les diverses méthodologies mises en œuvre développent les différentes déclinaisons du discours politique, en termes de supports, de conditions de production, de genres textuels.

On trouvera ainsi une analyse, fondée sur une série de discours compris entre 1959 et 1968, des mises en scène castristes de l'énonciation tutélaire de José Martí, intellectuel et militant nationaliste de la lutte contre l'impérialisme espagnol, dont le Líder Máximo voulut faire son double (Louise Bénat-Tachot). L'engouement presque magique de Castro pour la parole de Martí eut à disputer cette filiation contre l'appropriation que voulaient en faire les mouvements anticastristes. Les modalités citationnelles varient, ainsi que les conditions d'énonciation. Mais le fait constant est la «transmigration spirituelle» que Castro s'efforce d'opérer entre Martí et lui-même, et aussi la plasticité de la référence, qui oscille entre représentation messianique et dialectique marxiste, avant que ne s'impose la vision d'un Martí plus nettement bolivarien.

Non moins connue dans l'histoire récente du continent, la figure d'Augusto Sandino fut l'objet d'une réinterprétation qui refonda la cause révolutionnaire sandiniste dans les années soixante-dix (Jean-Henri Madeleine). La construction du guerrillero proletario est étudiée en détail à partir d'un article de Carlos Fonseca, qui dirigea la lutte du peuple nicaraguayen. On observe l'élaboration d'une figure à la fois exemplaire et lacunaire - ces lacunes étant liées à des conditions énonciatives particulières : effacement ou dispersion des sources, mais aussi instrumentalisation de la figure héroïque à des fins de consensus dans la situation de crise où est alors plongé le mouvement révolutionnaire.

En Argentine, c'est à une réinterprétation du péronisme que Néstor Kirchner se livre, en prenant le contre-pied de la politique de Carlos Menem qui se réclamait du même héritage politique (Morgan Donot). À travers cinq discours devant le Congrès, prononcés entre 2003 et 2007 , on constate que la figure tutélaire de Perón permet de substituer un justicialisme assagi, interventionniste et gestionnaire, à un justicialisme exalté, néolibéral et héroïque. Elle autorise aussi une synthèse entre personnalisation forte du pouvoir et ouverture démocratique. Une même référence permet ainsi à Néstor Kirchner de s'imposer

2. Ces contributions sont issues du colloque «Filiations, polyphonie, théâtralité dans le discours politique en Amérique latine», organisé par la SELP (Société d’étude des langages politiques), Université Paris Est Marne-la-Vallée, IHEAL, 12-14 février 2009. Voir le site de présentation du colloque [URL : http://infotext.free.fr/site/presentation_fr.htm]. Consulté le 11 mai 2010. 
comme le représentant tant d'une nouvelle génération politique que d'une mémoire sociale et nationale, ce qui pose la question de la réappropriation d'un discours historiquement dépassé dans des conditions économiques et politiques nouvelles.

La mesure du vocabulaire appuie la démarche de repérage des formules et des argumentations politiques. Suivant l'adjectif bolivariano au plus près des textes dans un corpus de presse vénézuélienne dans deux moments clés (Églantine Samouth), on découvre comment cet adjectif, constitutif du chavézisme, passe d'un sens général «qui a trait aux principes développés par Bolivar», au moment de l'accès au pouvoir de Hugo Chávez, à un sens engagé de «partisan de Chávez » lors de la tentative de coup d'État pour le renverser. L'adjectif glisse ainsi d'un emploi relationnel à un emploi qualificatif et prend une consistance axiologique. Fonctionnant parfois en quasi-synonymie avec l'adjectif chavista, il nimbe l'action gouvernementale d'une légitimité qui s'enracine dans une histoire mythifiée.

Dans une démarche quantitative diachronique portant sur un corpus de onze discours institutionnels du président Chávez de 1999 à 2007, on découvre (Maria Gonzalez et Pierre Fiala), sous ce que d'aucuns décriront comme le populisme bolivarien du discours chavézien, un projet plus structuré pour la gauche latino-américaine. L'article présente la place centrale - et contestée par les adversaires du régime - qu’y tient la figure légitimante de Simón Bolivar, à des fins de politique intérieure et, plus largement, continentale : l'efficacité du discours vient en partie de l'appropriation symbolique qui, imposant un modèle socialiste démocratique et égalitaire, prend les traits de l'idéal révolutionnaire du Libérateur.

Ce dossier ouvre des pistes et des méthodes qui s'inscrivent dans le débat actuel et renvoient aux autres contributions du colloque de $2009^{3}$. Ce n'est évidemment ni l'intégralité géopolitique d'un continent, ni l'exhaustivité d'une méthodologie ou d'une thématique qui sont visées ici, mais plutôt la recherche d'une transdisciplinarité, laquelle prend appui sur des pratiques discursives identifiées dans des textes que réunissent des corpus situés historiquement et socialement. L'approche conjointe du texte politique et de l'image dans des archives ou des réseaux vivants d'information et de communication, traditionnels ou numériques, l'analyse pragmatique des polyphonies médiatiques, des mises en scènes de figures mythiques, l'analyse quantitative et qualitative des propriétés lexicales, énonciatives, argumentatives, permettent de suivre dans le détail la construction de divers ethos discursifs de dirigeants politiques, actuels ou passés, de leurs rhétoriques, du pouvoir et des failles de leur éloquence.

3. L'ensemble des contributions de cette journée d'études figurent sur le site [http://site.adal. free.fr/spip/spip.php?rubrique14]. Consulté le 11 mai 2010. 


\section{Références}

Garibay David, Périès Gabriel éd., 2007, Violence et démocratie en Amérique latine, Mots. Les langages du politique, $\mathrm{n}^{\circ} 85$, octobre.

Rou QUIÉ Alain, 2010, À l'ombre des dictatures. La démocratie en Amérique latine, Paris, Albin Michel.

Couffignal Georges éd., 2009, Amérique latine. La nouvelle donne politique et économique, Mondes émergents, Paris, La Documentation française, IHEAL. 